\title{
Analysis on the Willingness of Job - seeking and Its Influencing Factors of Nursing Specialty in Higher Vocational Colleges
}

\author{
Jialin Guo ${ }^{1 . a}$, Xiaozhi Yang ${ }^{1 . b}$, Fei Wang ${ }^{1 . c}$, Shaoyang Liu ${ }^{1 . d}$ and Zhijun Zhao ${ }^{1 . e^{*}}$ \\ ${ }^{1}$ Luohe Medical College, Luohe, China \\ aSeahisence0210@126.com, byimu2008@126.com, cwhovering@yahoo.com, \\ d250492793@qq.com, ${ }^{*}$ Xulanglai@njau.edu.cn \\ *The corresponding author
}

\section{Keywords: Vocational colleges; Nursing; Employment intention; Influencing factors}

\begin{abstract}
To investigate and analyze the nursing employment intention and its influencing factors in higher vocational colleges. A self - made questionnaire was used to investigate the employment intention and influencing factors of nursing graduates in a medical college by means of cluster random sampling. $39.25 \%$ of the nurses who are willing to go to the grass-roots level are employed, followed by the grass-roots employment, the single factor analysis of the grass-roots employment intention, gender, educational system, internship experience, the source of the grassroots, And there was significant difference in the cognition of employment $(\mathrm{P}<0.05)$. The enthusiasm of grass-roots employment in higher vocational colleges is affected by sex, education experience, practice experience, cognition to the work of grass-roots work and pressure of employment and so on. We should strengthen teaching reform, increase basic practice teaching base construction, Community health service construction of the relevant policies, community nurses occupational environment and career planning should be an important teaching content.
\end{abstract}

\section{Introduction}

With the improvement of people's living conditions, the development of medical science and technology, nursing staff and hospital nursing post job category continues to increase, the social demand for nursing staff is also growing; At the same time, the occurrence of the change of disease and aging problem has also led to the increased demand for nursing staff. Grassroots areas in China compared to quantity and quality of the nursing staff and the city, there is a certain gap. In higher education enrollment rates rising, under the background of college students employment difficulty, for grass-roots employment has become an important direction of vocational college graduates employment [1-3]. With the deepening of the medical and health system reform in our country, and in grass-roots community health service institutions for local colleges and universities provide a new nursing graduates employment opportunities, cultivate high-quality nursing personnel for grassroots health institutions, maximum limit in the service of national medical and health institutions of the success of strategy is one of the important missions of local colleges and universities college of nursing. Therefore, the employment of nursing students in higher vocational college will also focus on the current nursing education and basic health services is one of the key [2-6]. This article will combine the writer in the medical college nursing for nearly 10 years working experience in counselor, through to the class of 2014 nursing graduates employment intention and influence factors of the investigation, nursing students series for grass-roots employment problem, now the results are as follows:

\section{The Object and the Method}

Investigation Object. Cluster sampling method is used to extract a medical college nursing graduates in Henan province of 400, including 18 of male, female 382, age 19-24 years old (average age $21.1+/-0.9$ ) and 287 rural students and urban students, 113, a three-year college, 296, two 
years, 104 people. All have all the theory courses, the participants are involved in nursing practice and practice, etc., all students to achieve the requirement of the school, to be able to graduate on time.

Method Survey tool (1) general information questionnaire, including gender, age, education, family address, family economic condition, etc. (2) refer to the related literature to nursing students grass-roots employment intention questionnaire design, including employment intention, willing to, don't want to the drivers of grass-roots employment and employment decision-making autonomy and so on question, divided into single and multiple choice of topics, with a small amount of subjective topic [2-5]. Questionnaire after into 50 selected objects for internal, the questionnaire of the overall internal consistency reliability coefficient, Cranach's alpha was 0.89 .

Survey respondents with class a questionnaire for the unit, a unified explanation method and the matters needing attention, the participants fill out on the spot, on the spot. This survey questionnaire 413, recycling, 406, 400 valid questionnaires, effective rate $98.5 \%$.

Statistical Methods. Spss17.0 statistical software was used for data analysis. Descriptive statistics and counting data was compared with the $\mathrm{x}^{2}$ test, and the significance level set at 0.05

\section{Results}

Vocational college nursing graduates employment intention at the grass-roots level and influencing factors of investigation and analysis are shown in Table 1.

Table 1 vocational college nursing graduates employment intention at the grass-roots level

\begin{tabular}{|c|c|c|c|c|c|c|c|c|c|c|}
\hline \multirow{2}{*}{ factors } & \multirow{2}{*}{$\mathrm{n}(\%)$} & \multicolumn{3}{|c|}{ Grass-roots employment intention } & \multicolumn{6}{|c|}{ Ideal employment intention } \\
\hline & & willing & $\begin{array}{l}\text { Not } \\
\text { willing }\end{array}$ & $\begin{array}{l}\text { Chi-cquare } \\
\text { value }\end{array}$ & $\begin{array}{l}\text { Large } \\
\text { hospital }\end{array}$ & Grassroots & Diverted & $\begin{array}{l}\text { PubMed / } \\
\text { abroad }\end{array}$ & other & $\begin{array}{l}\text { Chi-cquare } \\
\text { value }\end{array}$ \\
\hline \multicolumn{11}{|l|}{ gender } \\
\hline male & 18 & 2 & 16 & \multirow{2}{*}{$6.26^{*}$} & 11 & 2 & 2 & 2 & 1 & \multirow{2}{*}{7.16} \\
\hline Female & 382 & 155 & 227 & & 191 & 139 & 28 & 19 & 5 & \\
\hline \multicolumn{11}{|l|}{ Academic system } \\
\hline $\begin{array}{l}\text { Three years ( High } \\
\text { school starting point) }\end{array}$ & 296 & 93 & 203 & \multirow{2}{*}{$29.28^{*}$} & 181 & 91 & 8 & 14 & 2 & \multirow{2}{*}{$72.80 *$} \\
\hline $\begin{array}{l}\text { Two years }(3+2 \\
\text { college })\end{array}$ & 104 & 64 & 40 & & 21 & 50 & 22 & 7 & 4 & \\
\hline \multicolumn{11}{|l|}{ intern experience } \\
\hline $\begin{array}{l}\text { More than two } \\
\text { hospital internship }\end{array}$ & 219 & 56 & 163 & \multirow{2}{*}{$37.98^{*}$} & 138 & 47 & 18 & 14 & 2 & \multirow{2}{*}{$43.76^{*}$} \\
\hline $\begin{array}{l}\text { Less than three } \\
\text { hospital internship }\end{array}$ & 181 & 101 & 80 & & 64 & 94 & 12 & 7 & 4 & \\
\hline \multicolumn{11}{|l|}{ Students } \\
\hline Rural areas & 296 & 133 & 163 & \multirow{2}{*}{$15.42^{*}$} & 149 & 117 & 18 & 9 & 3 & \multirow{2}{*}{$21.35^{*}$} \\
\hline city & 104 & 24 & 80 & & 53 & 24 & 12 & 12 & 3 & \\
\hline \multicolumn{11}{|l|}{$\begin{array}{l}\text { Employment decision } \\
\text { - making autonomy }\end{array}$} \\
\hline Affected by others & 247 & 103 & 144 & \multirow{2}{*}{1.63} & 120 & 90 & 17 & 16 & 4 & \multirow{2}{*}{2.97} \\
\hline $\begin{array}{l}\text { Not affected } \\
\text { others }\end{array}$ & 153 & 54 & 99 & & 82 & 51 & 13 & 5 & 2 & \\
\hline \multicolumn{11}{|l|}{$\begin{array}{ll}\text { Cognition } & \text { of } \\
\text { Grassroots Work }\end{array}$} \\
\hline Positive evaluation & 160 & 97 & 63 & \multirow{2}{*}{$51.10^{*}$} & 55 & 79 & 14 & 8 & 3 & \multirow{2}{*}{$29.71 *$} \\
\hline Negative evaluation & 240 & 60 & 180 & & 147 & 62 & 16 & 13 & 3 & \\
\hline \multicolumn{11}{|l|}{$\begin{array}{ll}\text { Awareness } & \text { of } \\
\text { Employment } & \end{array}$} \\
\hline Employment pressure & 206 & 119 & 87 & \multirow{2}{*}{$61.08^{*}$} & 65 & 108 & 16 & 13 & 4 & \multirow{2}{*}{$67.25^{*}$} \\
\hline $\begin{array}{l}\text { Employment pressure } \\
\text { is not }\end{array}$ & 194 & 38 & 156 & & 137 & 33 & 14 & 8 & 2 & \\
\hline
\end{tabular}

Note: * the difference was statistically significant $(P<0.05)$. 


\section{Discussione}

The results showed that nursing girl's grass-roots employment rate is significantly higher than boys, it can be less with the nursing professional boys, and social demand is bigger. Two-year college "3 $+2 "$ nursing grass-roots employment intention ratio higher than the three-year college, the difference was statistically significant $(\mathrm{P}<0.05)$. Three-year college as the starting point for ordinary junior high school, has experienced the work of the college entrance examination, there is a clear goal and individual planning, also have strong job employment standards and advantage, self expectation higher employment, tend to be large medical institutions to their own development. 2-year nursing may have experienced clinical practice, to objectively understand the grass-roots work, when once again face the employment pressure, location clear, the targeted selection, grass-roots employment intention is higher. Internship experience, the following practice nursing students in tertiary hospital grass-roots employment intention is higher. This may be related to nursing students complete an internship in level 3 general hospital, large general hospital internship experience makes it to readjust the self employment expectation, development space is large, more can reflect its value factors to attract them to the large medical institutions. Students in rural areas at the grass-roots level will higher than urban students. In rural areas, in general, parents know about the overall employment environment and career choice behavior is less, and the growth environment, different employment expectations on nursing students. With grassroots work positively, think grass-roots employment intention high employment pressure. The current severe employment situation are important drivers of grass-roots employment trend of nursing students, to encourage college students to the basic national employment also introduced a lot of preferential policies, in order to promote nursing students to grass-roots employment has created good conditions for [3].

Employment decision-making autonomy from the results of the survey, most of the nursing students in employment decisions can self choice, this may be linked to the Internet in the information age, the improvement of the mobile phones and other communication facilities, sources of information channels and other factors.

Employment intention is the important psychological basis of graduate employment choice, different employment will lead to different employment expectations and selection, the survey showed, willing to the employment of nursing students was $39.25 \%$, the primary choice for the large hospital, the second is the basic unit employment, single factor analysis of grass-roots employment intention, different gender, schooling, internships, students, the cognition of grass-roots work, to the employment of the cognitive difference was statistically significant. Actively develop career education, make the nursing students correct understanding of the current employment situation, strengthen the professional sense of worth, make its positive for grass-roots employment, also note that the current college nursing graduates has been shown to develop relatively surplus, personnel distribution, difficult job trends, it is especially obvious in local colleges and universities graduates, in contrast is a lot of community health service institutions are difficult to recruit highly educated care people, the proportion of graduates in the actual in the community employment is still very low. Therefore guide part of local universities and colleges into the community employment of nursing students, let in large hospital employment difficult and excess slightly higher nursing talents with the rapid development of community health institutions to realize the better docking, in order to promote the better development of grassroots medical institutions have become college employment guidance is important subject need to be aware of. To strengthen the education of profession of nursing students, make the nursing students realize the employment situation, take the initiative to obtain employment information, correct positioning according to their own conditions, the personal self value realization is combined with social demand for employment, especially must pay attention to guide the college nursing students to the community employment (5-10]. This cause the vocational colleges should strengthen the teaching reform, we increase the construction of practical teaching base, strengthening the construction of community health services of the relevant policies, community nurses' occupational environment 
and career planning should become an important teaching content.

\section{References}

[1] TuLiJuan, zhang ping, phosphorus hole. 233 escort community nursing employment intention and driving factors analysis [J]. Journal of nursing, 2012, 6 (19) : 52-56.

[2] Qiu Xueqin, zhang ping, phosphorus hole. Nursing students of local colleges and universities community nursing employment intention and influencing factors of survey $[\mathrm{J}]$. Journal of qilu nursing journal, 2013 (7) : 64-66.

[3] hai-yan yu, ju-en huang, liu jing etc. Higher vocational nursing students community nursing employment intention and influence factors analysis [J]. Journal of health vocational education, 2016, 9 (34) : 104-106.

[4] sviri ge, brilliant red treasure. Higher vocational graduates to the grass-roots employment problems and advice [J]. Journal of liaoning vocational college, 2010, 12 (2) : 106-107.

[5] ZhangYan, wang lei. Clinical medicine professional undergraduate course graduate basic investigation and analysis are greatly [J]. Journal of the Chinese general medicine, 2008 (11) : 1181-1182.

[6] maike. Different education level of the community care nurses will compare [J]. Journal of binzhou medical college, 2013, 4 (5) : 363-365.

[7] xian-hong huang, Lin Lujing, king and etc. Medical students grass-roots employment intention and influence factors analysis [J]. Journal of grassroots health, 2014, 7 (8) : 46-50.

[8] JinYuan, yun-peng wang, wei, etc. When the building the mechanism of medical college graduates to the grass-roots employment [J]. China's school education, 2010 (7) : 35 and 36.

[9] YanLei ying-mei sun. The way of medical graduates employment at the grass-roots level selection [J]. Journal of Chinese higher medical education, 2009, (6) : 117-118.

[10]Tang, Chen lei, Yang Juan. A medical school nursing undergraduate community employment cognitive status survey [J]. Journal of health services at the grass-roots level, 2016 (19) : 190-192. 